\title{
A renúncia da mãe: sobre gênero, violência e práticas de Estado
}

\section{The renouncing of the mother: about gender, violence and state practices}

\author{
Roberto Efrem Filho',"I \\ https://orcid.org/0000-0001-9438-0080 \\ robertoefremfilho@yahoo.com.br \\ Breno Marques de Mello ${ }^{\prime \prime \prime}$ \\ https://orcid.org/0000-0003-3689-087X \\ brenode@hotmail.com \\ ' Universidade Federal da Paraíba - João Pessoa, PB, Brasil \\ " Universidade Federal de Pernambuco - Recife, PE, Brasil \\ III Pesquisador independente - João Pessoa, PB, Brasil
}




\title{
Resumo
}

No presente ensaio etnográfico, pretendemos explorar analiticamente a renúncia da mãe e seus efeitos em certas práticas e constrangimentos de Estado, ao tempo que procuramos dimensionar essa "mãe" como sujeito profundamente implicado em nossa frágil experiência democrática. Apostamos na ideia de que as mais recentes e cortantes disputas pelos limites de nossa democracia têm a "mãe" em seu cerne. Para tanto, valemo-nos da análise de quatro excertos narrativos. Dois desses excertos se relacionam às narrativas de Marcela sobre a sua conturbada relação com Ricardo, o seu filho mais velho, adolescente. Os dois outros excertos narrativos decorrem de episódios que vivenciamos durante o pleito eleitoral de 2018, o qual resultou na eleição de Jair Bolsonaro à presidência do Brasil.

Palavras-chave: maternidade; violência; Estado; democracia.

\begin{abstract}
This ethnographic essay intends to analytically explore the renouncing of the mother and its effects on certain state practices and constraints, while trying to dimension this "mother" as a subject who is deeply tied to our fragile democratic experience. The main hypothesis is that the most recent and sharp disputes over the limits of our democracy have projected the "mother" at the core of the issue. To this end, four narrative excerpts were analyzed. Two of them are Marcela's narratives about her troubled relationship with Ricardo, her eldest son, a teenager. The two other narratives stem from episodes experienced during the 2018 electoral campaign, which led to Jair Bolsonaro's election to the Brazilian presidency.
\end{abstract}

Keywords: motherhood; violence; State; democracy. 
A figura da "mãe" tem oportunizado relevantes debates nas ciências sociais brasileiras e, sobretudo, no campo dos estudos de gênero e sexualidade. ${ }^{1}$ Nestes, parte de nossas reflexões ressaltam, por exemplo, a proeminência daquela figura na formulação de e no acesso a políticas públicas e de assistência social, como o Bolsa Família e o Minha Casa Minha Vida (Costa, 2002; Klein, 2005; Mariano, Carloto, 2009; Nanes; Quadros, 2018; Pires, 2012). Outros de nossos empenhos analíticos têm enfatizado a mobilização da "mãe" em lutas por direitos e justiça implicadas em disputas acerca da legitimidade de determinadas vítimas de violência (Araújo, 2007; Efrem Filho, 2017b; Farias, 2014; Lacerda, 2014; Leite, M., 2004; Vianna, 2014; Vianna; Farias, 2011); em contextos de punição e encarceramento (Lago, 2019; Leite; Marinho, 2020; Ribeiro, 2020) ou de emergências de saúde pública (Pinheiro; Longhi, 2017; Scott; Lira, 2020).

Os mais interessantes desses trabalhos localizam a "mãe" no interior de conflitos sociais e práticas de Estado em que gênero e sexualidade aparecem tanto como elementos tensionadores, geradores de controles e agenciamentos, quanto como linguagem através da qual outras relações sociais - de classe, racialização, territoriais, geracionais, etc. - articulam-se e se exprimem. Nesses trabalhos, a figura da "mãe" é normalmente apreendida por sua performatividade, ou seja, pelos esforços políticos de sua constituição em meio àqueles conflitos sociais e práticas de Estado. Assim, tem-se notado que mães, familiares de vítimas e mesmo movimentos sociais se esforçam para corresponder às convenções morais em torno da "mãe" e, desse modo, movimentarem-se politicamente. Além disso, tem-se perquirido os modos de constituição da "mãe" como uma positividade axiológica apriorística, tendo em vista que sua invocação ocorre, nas disputas de que nossos trabalhos tratam, porque nelas se pressupõe a validade da "mãe". A "mãe" parece funcionar como um operador ideal de

1 Versões anteriores e diferentes deste artigo foram apresentadas no Simpósio Especial 5 “Gênero e Sexualidade: conservadorismos, violência e ativismos", coordenado por Isadora Lins França e Sérgio Carrara junto à $31^{\mathrm{a}}$ Reunião Brasileira de Antropologia, em dezembro de 2018, e no Simpósio Temático 38 "Sexualidade e Gênero: política, agenciamentos e direitos em disputa", coordenado por Regina Facchini e Roberto Marques junto ao $43^{\circ}$ Encontro Anual da Anpocs, em outubro de 2019. Agradecemos enormemente a Isadora, Sérgio, Regina e Roberto pelas discussões e aprendizados; e a Maria Filomena Gregori e Adriana Vianna pelos cuidadosos comentários ao texto nessas ocasiões. Agradecemos, enfim, às pareceristas anônimas do artigo e a Claudia Fonseca, Diana Marre e Fernanda Rifiotis pela oportunidade - uma felicidade - de compor este dossiê. 
políticas públicas - é ela quem recebe a bolsa, é ela quem recebe a casa - como parece funcionar nas contendas a respeito da morte de alguém cuja legitimidade é posta em questão. Há desejo pela "mãe". "De Estado", inclusive.

Entretanto, pouco temos pensado sobre a sua recusa: e quando uma mãe renuncia a "mãe"? No presente ensaio etnográfico, pretendemos explorar essa renúncia da mãe e seus efeitos em certas práticas e constrangimentos de Estado, ao tempo que procuramos dimensionar essa "mãe" - mas, especialmente, a "mãe solteira" - como sujeito profundamente implicado em nossa frágil experiência democrática. Apostamos na ideia de que as mais recentes e cortantes disputas pelos limites de nossa democracia mantêm a "mãe" em seu cerne. Para tanto, valemo-nos da análise de quatro excertos narrativos. Dois desses excertos se relacionam às narrativas de Marcela $^{2}$ sobre a sua conturbada relação com Ricardo, o seu filho mais velho, adolescente. Os dois outros excertos narrativos decorrem de episódios que vivenciamos durante o pleito eleitoral de 2018, o qual resultou na eleição de Jair Bolsonaro à presidência do Brasil. ${ }^{3}$

A análise desses excertos inspira-se na ideia de que as narrativas ali presentes compõem uma "história coletiva", como a designou Claudia Fonseca (2012) ao tratar do que chamou de história silenciada das "mães 'abandonantes'". Marcela e as mães que atravessam os quatro excertos narrativos de que nos ocupamos neste texto não restam sozinhas, portanto: são também "mulheres que estavam negociando os difíceis termos de uma maternidade tida como fora do lugar" (Fonseca, 2012, p. 15). Ademais, a análise que aqui desenvolvemos procura localizar-se em meio aos recentes e imprescindíveis esforços de oferecer, a partir de pesquisas etnográficas, chaves de inteligibilidade para a consolidação

2 Neste artigo, ficcionalizamos e mantivemos em itálico os nomes próprios de nossa interlocutora de pesquisa, de alguns sujeitos por ela mencionados e de determinados locais em que transitam, com vistas à sua proteção. Por sua vez, deixamos entre aspas as categorias êmicas e as expressões sob rasura - como "mãe" - assim como trechos das falas de Marcela e as citações diretas a autores localizadas no corpo do texto.

3 A entrevista com Marcela contou com a assinatura de um termo de consentimento livre e esclarecido e, conduzida pelos dois autores, ocorreu em meio ao trabalho de campo da pesquisa de mestrado de Breno Marques de Mello, realizada junto ao Programa de Pós-Graduação em Ciências Jurídicas da UFPB (Mello, 2019) e financiada com bolsa pelo CNPq. Durante o artigo, são também citadas informações sobre Marcela colhidas anos antes, durante a pesquisa doutoral de Roberto Efrem Filho, desenvolvida junto ao Programa de Pós-Graduação em Ciências Sociais da Unicamp (Efrem Filho, 2017a), e com a qual Marcela também consentiu formalmente. 
do conservadorismo e a atual crise democrática brasileira. ${ }^{4}$ Optamos metodologicamente pela etnografia como recurso para pensar processos de Estado e a experiência democrática porque acreditamos, seguindo Gabriel Feltran (2020), que "das margens compreende-se melhor esse novo centro", assim como visualizamos que relações de gênero e de sexualidade operam densamente nessas margens e centros, figurando a "mãe" e os conflitos em torno das fronteiras democráticas.

\section{Primeiro excerto}

[18 de julho de 2018, 21h20, WhatsApp, mensagem de áudio de Breno para Roberto.] "Beto, notícias de Marcela". Nós dois não sabíamos de Marcela já há alguns anos, ao menos desde 2015, quando ela deixou o prédio da Ocupação Horizonte e se mudou para o seu apartamento próprio, conseguido através do Programa Minha Casa Minha Vida. Marcela havia sido uma das lideranças da Ocupação iniciada em abril de 2013 num prédio abandonado de um antigo hotel localizado no centro de João Pessoa. Àquela época, o Núcleo de Extensão Popular Flor de Mandacaru - o núcleo de assessoria jurídica universitária popular que Breno compunha ainda como estudante de graduação em Direito e Roberto, como professor, orientava - acompanhava as demandas jurídicas da Ocupação Horizonte e, por isso, nós dois acabamos aproximando-nos bastante de Marcela, que, por diversos motivos, tornar-se-ia uma interlocutora importante da pesquisa de doutorado de Roberto. Agora, em julho de 2018, no entanto, três anos após deixar de ser uma sem-teto, Marcela procurava Breno por razões inesperadas: ela precisava saber se poderia ser presa por não querer mais cuidar do seu filho mais velho. "Não, é porque ele me espancou, Breno, tá pintando o sete em Mandacaru, no tráfico, em todo canto, e eu disse ao promotor que não iria mais cuidar dele. Ele foi pra Areia, pra casa da avó, mas tá pintando o sete lá também na casa da avó, ameaçou todo mundo da família de morte,

4 Como exemplos desses esforços, podemos citar os recentes trabalhos de Gabriel Feltran (2020), Vanessa Leite (2019), Roberto Efrem Filho (2019), Letícia Cesarino (2019) e Ronaldo de Almeida (2019). Para uma perspectiva da crise democrática a partir das implicações de movimentos de mães e familiares de vítimas de violência institucional, sugerimos ainda o trabalho conjunto de Juliana Farias, Natália Lago e Roberto Efrem Filho (2020). 
inclusive a mim. E depois que ele me espancou, eu não quero mais conversa com ele. Mas o promotor disse que vai me processar e eu quero saber se eu vou ser presa por não querer mais cuidar dele." Na mensagem de áudio, Breno contava a Roberto que tentou explicar a Marcela que o procedimento não era aquele, mas ela estava muitíssimo preocupada com a possibilidade de ser presa por não querer cuidar do filho. "Tava com medo de ser processada, perguntando qual era a pena, se era de prisão, se era pagar lata de leite, se era fazer trabalho, trabalho alternativo, pena alternativa na verdade, porque ela estava disposta a fazer qualquer coisa para não cuidar do menino, que só tem 14 anos, inclusive."

\section{Segundo excerto}

[17 de setembro de 2018, Sindicato da Habitação (Secovi), São Paulo.] Às vésperas do primeiro turno das eleições de 2018, o general Hamilton Mourão, candidato à vice-presidência do país na chapa de Jair Bolsonaro, proferiu uma palestra durante um almoço oferecido a um grupo de empresários do setor de habitação. Àquela ocasião, ao apresentar sua interpretação a respeito dos cenários alarmantes de criminalidade e violência no Brasil, o general Mourão afirmou que famílias pobres compostas apenas por mãe e avó, mas sem pai e avô, consistem em "fábricas de desajustados" predispostos a ingressar no "narcotráfico": "A partir do momento em que a família é dissociada, surgem os problemas sociais. Atacam eminentemente nas áreas carentes, onde não há pai e avô, é mãe e avó. E, por isso, torna-se realmente uma fábrica de elementos desajustados que tendem a ingressar nessas narcoquadrilhas."

\section{Terceiro excerto}

[19 de setembro de 2018, página do Twitter de Jair Bolsonaro.] Dois dias após as declarações do general Hamilton Mourão provocarem grande polêmica e ameaçarem a campanha de Bolsonaro à presidência, especialmente junto ao eleitorado feminino, o então candidato publicou um vídeo em suas redes sociais. No vídeo, que apresenta uma estética propositadamente amadora e se inicia com a frase "essa é uma história de verdade", o candidato fala sobre sua esposa 
e a decisão de terem a filha mais nova, Laura, que Bolsonaro havia descrito, em abril de 2017, como resultado de uma "fraquejada" após as desejadas concepções dos seus quatro filhos homens. A "história de verdade" começa então com um fundo musical terno proporcionado pelo som de um teclado - típico dos momentos de testemunho existentes nos cultos de igrejas evangélicas - e um Bolsonaro sorridente e espontâneo dizendo que "educar um filho homem é fácil, né? Vai jogar bola, dá um carrinho nele, fala palavrão também, e quando vem uma mulher é diferente. É completamente diferente." A essa altura do vídeo, Bolsonaro resolve empreender uma "confissão". "Inclusive, é uma confissão, né? Eu já estava..." Nesse momento, Bolsonaro se cala, parece travar diante da câmera, perder as palavras. O fundo musical vai desaparecendo até que a imagem resta completamente em silêncio. Seis segundos depois, Bolsonaro sorri de novo, emocionado, mas logo desfaz o sorriso e volta àquela seriedade comovida enquanto o vídeo permanece em silêncio. Então, mais sete segundos após, o fundo musical retorna alto e o candidato retoma a fala: "Eu já tinha decidido não ter mais filhos. Estava vasectomizado. E havia combinado isso com a minha esposa. Já tinha uma filha. Eu tenho uma enteada em casa, né? A minha esposa era mãe solteira. Ela falou até pela manutenção, né? Que a realização de grande parte das mulheres é ter filhos, né? E eu fui no hospital central do exército, desfiz a vasectomia. Mudou, sim, muito a minha vida com a chegada da Laura, e eu agradeço a Deus e a minha esposa por ela." A imagem de Bolsonaro sai e é substituída por um vídeo de celular em que o próprio candidato se filma ao lado de Laura, sua filha. A menina alegre diz "te amo", o pai pede um beijo e Laura, em resposta, beija-o no rosto. "Valeu, pessoal, um abraço em todo mundo aí." O vídeo se encerra.

\section{Quarto excerto}

$\left[1^{\circ}\right.$ de novembro de 2018 , casa alugada em que Marcela vive com o companheiro e as filhas no bairro de Mandacaru, região periférica de João Pessoa.] Preocupados com Marcela e interessados em compreender o que havia acontecido, nós marcamos de encontrá-la em sua casa. Fazia um ano, Marcela e sua família precisaram deixar o apartamento do conjunto habitacional em que moravam, resultado de sua inserção no Programa Minha Casa Minha Vida, porque os 
três andares de escadas do edifício impediam que Janine, a filha mais velha de Marcela, gravemente ferida em um acidente de trânsito enquanto andava de bicicleta, entrasse e saísse de casa em suas incontáveis idas e vindas de hospitais e sessões de fisioterapia. Marcela nos recebeu na pequena sala de sua casa de quatro cômodos - quarto, sala, cozinha e banheiro - e conversou conosco enquanto a filha mais nova, de pouco mais de dois anos, brincava no corredor da vila, bem ao nosso lado. Ali, Marcela nos contou que, ainda quando estavam no apartamento, Ricardo veio morar com ela. Ricardo é o filho mais velho de Marcela e, desde muito pequeno, mora com a avó, mãe de Marcela, numa cidade do interior da Paraíba. Mãe e avó decidiram, todavia, pela mudança de Ricardo para João Pessoa depois de o menino "começar a fazer coisas que não se deve". Ricardo, no entanto, não queria morar com a mãe e, depois de chegar a fugir, convenceu a avó de que se comportaria melhor e poderia voltar para o interior. Voltou. "Não deu um mês, aprontou de novo. [...] Roubou o celular do vizinho." Marcela, então, trouxe novamente o filho para perto de si. Mas "ele queria tá assim, virado da cabeça, na pracinha, não queria estudar, queria tá se drogando". O comportamento de Ricardo colocava Marcela em estado permanente de conflito com o filho. Numa ocasião, quando ainda moravam no condomínio, após levar umas "lamboradas" da mãe por haver feito algo que a desagradou, Ricardo pegou um garfo para furar Marcela. "Só que eu não vi. Quem viu foi Janine. Janine não deixou. Só que eu senti que ele queria vir pra cima de mim." Meses depois, contudo, já na casa de Mandacaru, diante de um novo conflito e de novas "lamboradas", Ricardo se aproveitou de um instante em que Marcela estava de costas para atacar a mãe. "Aí, nesse dia, ele me deu uma sessão de murro aqui que eu caí, fiquei caída aqui." Ricardo continuou surrando Marcela enquanto ela estava caída no chão. Segundo Marcela, quando ele percebeu que ela se levantaria, Ricardo correu, deixou a casa e "passou a noite no mundo". No dia seguinte, ao meio-dia, reapareceu. Marcela, porém, disse ao filho que ele só voltaria para casa se apanhasse. "Se eu lhe der uma pisa, eu vou lhe mostrar que eu sou sua mãe. Se você não quiser mãe, olhe aí, a porta da rua é a serventia da casa." Ricardo se negou a apanhar. Disse que não voltaria para casa, que odiava Marcela. "E isso se drogando, né?" Marcela, assim, decidiu procurar o Conselho Tutelar, preocupada com o filho e com as consequências, inclusive para ela, de o menino estar na rua. No Conselho, Marcela ouviu que tinha de prender o filho em casa, que não poderia deixar de cuidar do filho, que tinha, por obrigação, 
de ficar com ele. "Então, eu prefiro ir presa do que tomar de conta dele. Agora, vocês vão ter que tomar de conta dos meus outros filhos." Ricardo não voltou para a casa da mãe. Continuou circulando por Mandacaru, contando com a ajuda de alguns vizinhos, até que, com quatro meses de Ricardo na rua, Marcela soube que queriam matá-lo. "Mas por que queriam matar?" "Safadeza já aí. Fazendo coisa, gesto de facção." Roberto pergunta se ele estava na Okaida, uma das facções que compõem o mercado de drogas na Paraíba e atua em Mandacaru. Rindo, Marcela fala que "ele diz que é da Okaida". Também rindo, Breno pergunta se ela acredita que ele realmente é da Okaida. Marcela responde que não. "Ele não tá se envolvendo com os vagabundo da Okaida, porque se ele tivesse se envolvendo com vagabundo da Okaida, eu não vou mentir não, a primeira coisa que ele tinha feito, ele tinha arrumado uma arma e tinha vindo me matar." Ameaçado de morte, Ricardo voltou para a casa da avó, no interior. Lá, contudo, continuou "dando dor de cabeça" e acabou detido, com duas armas de brinquedo e uma moto roubada, assaltando numa cidade próxima. Logo, Marcela precisou viajar para a cidade da mãe e ir à Vara da Infância, apresentar-se diante do juiz, numa audiência. No dia da audiência, porém, Ricardo se negou a ir ao fórum. "Ele ameaçou se jogar do colégio embaixo." Negou-se, não foi. Na audiência, no entanto, Marcela precisou dizer e redizer ao promotor de Justiça que preferia ir para a cadeia do que ficar com o filho. "Porque ele é ruim. Um filho quando bate na mãe ou quando vem dizer que odeia pai e mãe, ele já tá dizendo quem ele é, por que o senhor não interna ele?" O promotor, entretanto, insistiu no argumento de que Marcela não poderia abrir mão do filho. "Você quer que eu leve ele pra minha casa?" - perguntou o promotor. "Não, não tou querendo que o senhor leve ele pra sua casa, não." "Então você tem que levar ele pra sua casa." "Pra minha casa mesmo não, que eu não vou criar marginal" - retrucou Marcela. "Então por que você não pegou uma tora de pau e quebrou ele de pau?" "Pra quê? Se eu tivesse quebrado ele de pau, deixado ele mole de pau, vocês tinham ido na minha porta me prender." Impressionado com o que Marcela nos contava, Breno perguntou: "E ele mandou tu bater no teu filho?" Marcela confirmou. Fato é que o impasse entre Marcela e o promotor somente se resolveu quando, também na audiência, a avó anunciou que assumiria a guarda do neto. Mesmo preocupada com a mãe idosa, Marcela aceitou a sua decisão. Estava absolutamente convencida de que não queria o filho consigo. "Ele é ruim, ele é ruim. Ele tem o instinto do pai dele." 


\section{A “mãe" como prática de Estado}

A renúncia de Marcela a cumprir com o seu pressuposto papel de "mãe de Ricardo" aciona um cansativo ciclo de "constrangimentos de Estado" que provocam desconforto e embaraço, assim como restringem, comprimem e induzem sujeitos e suas possibilidades de ação. Na história narrada por Marcela, esses constrangimentos remetem à pergunta empreendida por Adriana Vianna (2002a, 2002b) em sua tese de doutorado: "Quem deve guardar as crianças?" No entanto, tais constrangimentos de Estado parecem obliterar as possibilidades de resposta na medida em que os "especialistas", autorizados a desempenhar o que Vianna chama de "ação tutelar" e "produção de destinos", negam-se a oferecer outro caminho para Ricardo - um "menino que dá problema" - que não seja a própria "mãe", Marcela. A insistência dos conselheiros tutelares, do promotor de Justiça e do magistrado no dever inexorável de Marcela de assumir o trabalho de cuidado sobre seu filho mais velho comunica, a um só tempo, o peso das convenções morais de gênero que recaem sobre Marcela, coagida à maternidade, e certa indisposição de Estado em encontrar soluções para um "problema" que tangencia processos de criminalização e que, de acordo com a própria Marcela, não tem lá muita solução. "Ele é ruim”, afinal. "Por que o senhor não interna ele?"

As convenções de gênero que sustêm a inexorabilidade da "mãe" para o trabalho de cuidado remetem à suposição da existência de um vínculo inextrincável entre uma mãe e um filho. Como percebeu Bila Sorj (2016), esse vínculo com força de essência justifica a atribuição à maternidade de uma credibilidade ou de uma "autoridade moral" com competência singular para o exercício do "resgate". Isso significa que se pressupõe tanto a existência de uma ligação natural e incontestável entre mães e filhos quanto uma capacidade materna de fazer essa ligação valer ao extremo, inclusive através do esforço para retirar o filho dos perigos do crime, da violência ou da injustiça. Em consequência, a hipótese da quebra desse vínculo é rejeitada de pronto, com análoga força de essência. É que, como notou Camila Fernandes (2017, p. 203), embora "dar" ou "abandonar" um filho consista em um gesto provável, e até admitido em contextos específicos, "por outro lado, o ato se materializa como última fronteira do impensável feminino". Assim, as mães que o cometem acabam por incidir em desordens de gênero e por tornar-se o que Fernandes (2017) chamou de "figuras 
de causação", mulheres lidas como personagens de descuido e perturbadoras do cotidiano, potenciais catalisadoras dos constrangimentos de Estado de que estamos falando.

A enérgica discussão entre Marcela e o promotor de Justiça, discussão que levaria Marcela a telefonar para Breno ainda desesperadamente preocupada com a possibilidade de ser presa, é emblemática desses constrangimentos. Ratificando o dever de Marcela de ser mãe, mas precisando lidar com o incômodo fato de sua recusa, o promotor pergunta se deveria ele levar Ricardo para casa, numa manobra retórica que conduziria Marcela a reconhecer, constrangida, que apenas ela teria a responsabilidade de gerir o enorme "problema" que é seu filho. Marcela responde, todavia, num novo gesto retórico, que não levará para casa um "marginal" - atualizando, de certo modo, a famosa frase normalmente dita por aqueles que se põem "contra os direitos humanos". É nesse instante que, segundo o que Marcela nos contou, o promotor questiona, no extremo daqueles constrangimentos, o porquê de ela não se ter valido de violência contra o filho. E Marcela, sagaz, contra-argumenta que, se fizesse isso, ela mesma restaria presa - algo que um promotor de Justiça a priori deveria saber e que Marcela provavelmente sabe em razão de sua proximidade com o que Fernanda Cruz (2015, p. 336) denominou como "linguagem das políticas de proteção", a qual mantém na figura do Conselho Tutelar uma referência fundamental. ${ }^{5}$

Essa cobrança do promotor a Marcela, a de que ela deveria ter empregado violência física contra o filho - "então por que você não pegou uma tora de pau e quebrou ele de pau?" -, alude à ilegal disponibilidade do corpo adolescente para a violência correcional. Esta violência corresponde a um recurso doméstico que, como Adriana Vianna (2002a) notou, alcança "limites morais intoleráveis" em determinados casos judiciais, levando mesmo à perda da guarda da criança, mas pode ser contemporizado ou silenciado em outros casos. Sendo

5 Segundo Fernanda Cruz (2015), suas interlocutoras de pesquisa - jovens mães "egressas" de serviços de acolhimento institucional - familiarizadas com a mencionada linguagem das políticas de proteção, e sobretudo com as lógicas de operação dos Conselhos Tutelares, tentam subverter o papel desse agente e buscam formas de proteger seus filhos das práticas estatais de intervenção. Marcela, todavia, diante de sua decisão de renunciar aos cuidados de seu filho mais velho, resolveu procurar o Conselho Tutelar antes mesmo de se voltar ao Sistema de Justiça. Era com o Conselho que ela estava inicialmente preocupada e, ao mesmo tempo, era no Conselho que ela imaginava alcançar uma solução para as suas preocupações com Ricardo. 
assim, a implicação de agentes do Sistema de Justiça na aceitação tácita ou na contemporização de práticas de violência contra crianças e adolescentes não é excepcional - lembremos, por exemplo, do que acontece frequentemente nas instituições de internação de "adolescentes em conflito com a lei" (Mallart, 2014; Montes-Maldonado, 2020; Rocha, 2016) -, porém, a assunção tão explícita da possibilidade da surra, por parte do promotor de Justiça, provocou em nós o espanto que se expressou na pergunta de Breno: "E ele mandou tu bater no teu filho?"

Àquele momento da entrevista, Marcela já havia relatado algumas cenas de violência doméstica protagonizadas por ela contra Ricardo. Nós, portanto, já sabíamos inclusive que, depois da agressão que a deixou no chão, a condição estabelecida por Marcela para a volta do filho para casa foi a de uma nova "pisa". "Se eu lhe der uma pisa, eu vou lhe mostrar que eu sou sua mãe. Se você não quiser mãe, olhe aí, a porta da rua é a serventia da casa." Nós, portanto, sabíamos que o acionamento da violência era comum para Marcela, assim como sabíamos há tempo que, anos atrás, ela própria foi vítima de atos de violência física cometidos pelo pai de Ricardo. De certa maneira, àquela altura, nós talvez já até localizássemos toda aquela saturação de violência no interior da "economia das intensidades" de que trata Camila Fernandes (2017, p. 152), nos modos "como se fabricam sujeitos e pessoas morais envolvidos em dinâmicas de exaustão e tensão emocional".

Entretanto, a cobrança do promotor de Justiça para que Marcela exercesse a violência física contra seu filho parecia exceder os limites mínimos do fazer judicial. Por isso, o nosso espanto. Por isso, também, a resposta que Marcela ofereceu ao promotor. Com ela, Marcela expunha as contradições da cobrança, sobretudo o fato de que sua realização implicaria no cometimento de um crime que levaria à penalização da mãe: "Pra quê? Se eu tivesse quebrado ele de pau, deixado ele mole de pau, vocês tinham ido na minha porta me prender." Mas, a despeito da citada sagacidade da resposta, a preocupação de Marcela quando da réplica ao promotor não parecia ser exatamente a de ser presa. Ou não apenas. É que Marcela temia a morte. A sua morte pelas mãos de Ricardo. A morte de Ricardo por conta das facções.

A exigência do promotor de que Marcela deveria necessariamente cuidar de Ricardo, valendo-se inclusive de violência física, dispunha também o corpo de Marcela à violência. Era disso sobremaneira que Marcela se esquivava. 
A mãe relatava, afinal, que fora espancada pelo filho, que tinha medo dele, que não queria conviver com Ricardo. Apesar disso, porém, todos os agentes de Estado com que Marcela se deparou reafirmaram a inescapabilidade do trabalho de cuidado, ou seja, dispuseram o corpo de Marcela à probabilidade de que o medo da mãe se concretizasse, o medo de que Marcela voltasse a apanhar. Mas o promotor avança, como visto, nessa disponibilização dos corpos às práticas de violência ao passo que, com a cobrança, define ser a violência um recurso admissível de gestão do "problema", recurso este que deve ser operado pela mãe, aquela cuja convivência com o filho já a coloca num estado de violência latente.

Não é difícil perceber, tal disponibilização dos corpos à violência consiste numa dimensão dos processos de racialização com que os sujeitos pertencentes aos setores mais jovens e precarizados da classe trabalhadora convivem cotidianamente em nosso país. Os constrangimentos de Estado que disponibilizam Marcela e Ricardo à violência como forma de gestão do "problema" do "menino que dá problema" se encontram imbricados às "engrenagens" do "governo de mortes" de que tratou Juliana Farias (2014). Essa imbricação se demonstra tanto na conformação de tipos de sujeitos violentáveis quanto nos modos como as práticas de violência vinculadas às dinâmicas do mercado de drogas e de sua criminalização num contexto de desigualdades (Feltran, 2011) conectam-se a experiências de violência doméstica: "Porque se ele tivesse se envolvendo com vagabundo da Okaida, eu não vou mentir não, a primeira coisa que ele tinha feito, ele tinha arrumado uma arma e tinha vindo me matar." Assim, aqui, esses processos de racialização se fazem notadamente através de relações de gênero que não só permitem que a mãe seja violentável, mas a compreendem como uma instância de exercício de violência e controle.

A insistência narrativa de que Marcela não possui alternativa, a não ser a de levar Ricardo novamente para casa, sob sua guarda e seus cuidados, sinaliza que Marcela é, ela mesma, um agente e um objeto de controle, alguém apto a realizar o esforço de ordenação, ainda que se valendo de violência, e a ser ordenado, inclusive através da disponibilização do seu próprio corpo à violência. Em outras palavras, a "mãe" é uma prática de Estado. Situa-se, dessa maneira, naquele "duplo fazer do gênero e do Estado" de que têm tratado Adriana Vianna e Laura Lowenkron (2017): a maternidade posta "em ato" deve engendrar a competência para a violência, para sofrê-la ou exercê-la, algo cuja legitimidade, 
ao menos normativamente, decorreria da presunção do monopólio estatal. ${ }^{6}$ Em certo sentido, a "mãe" exerce aquilo que María Gabriela Lugones (2017) chamou de "gestão maternal da proteção estatal", uma vez que compete a ela prioritariamente a administração do "menino que dá problema" e tangencia o crime. $\mathrm{E}$ isso no limite do sacrifício da vida, portanto, do que se espera verdadeiramente de uma "mãe". Se a "mãe" falha, se o processo de criminalização se aprofunda - "por que o senhor não interna ele?" -, resta a ela ainda servir de justificativa para os altos índices de criminalidade e violência no país, operadora privilegiada de uma "fábrica de elementos desajustados", como caracterizou o general Mourão.

A invocação da "ausência do pai" durante a palestra de Hamilton Mourão naquele 17 de setembro de 2018, na sede do Sindicato da Habitação de São Paulo, é emblemática da conversão da "mãe" em agente e objeto de controle. Em sua declaração, o general incorreu em um enquadramento parecido com aquele empreendido pelos antropólogos ingleses implicados no que se chamou de "A Polêmica do Nascimento Virgem", os quais demonstravam intensa preocupação com a "ausência do pai" nos modos como nas Ilhas Trobriand compreendia-se o ato da concepção. Segundo Marilyn Strathern (1995), contudo, a ausência em questão derivava do ponto de vista euro-americano e, logo, da preocupação dos próprios antropólogos ingleses com a atribuição do pai naquele ato. Analogamente, Mourão se ressente de uma falta com a qual as mulheres dos setores mais precarizados da classe trabalhadora brasileira se arranjam desde sua constituição como classe.

Dados recentes do IBGE, colhidos em 2015, apontam a existência de 11,6 milhões de arranjos familiares compostos por mães solo e seus filhos. Dentre as famílias com filhos, $26,8 \%$ são compostas pela mãe e seu(s) filho(s); $15,7 \%$ são compostas por um casal e seu(s) filho(s) tendo a mulher como referência; $53,9 \%$ são formadas pelo casal e seu(s) filho(s) tendo o homem como referência;

6 Esta presunção do monopólio da violência é dimensão fundamental da ideia de Estado e se relaciona profundamente a processos de criminalização, visto que o "crime" funciona abstratamente como justificativa para que, em reação, "o Estado" mobilize o referido monopólio (Efrem Filho, 2017c). Interessa-nos aqui notar, no entanto, a posicionalidade da "mãe" nesse processo de Estado, situada naquilo que Birman e Pierobon (2021) recentemente definiram como sendo "o lugar 'entre" figuras a priori identificadas com a ordem estatal e com o crime, em contextos de violência. 
e 3,6\% são formadas pelo pai solo e seu(s) filho(s). Quase um terço das famílias brasileiras com filhos prescindem do "pai", portanto.? Mas essa prescindibilidade não consiste numa novidade histórica. Ao analisar autos de processos judiciais relativos a disputas pela guarda de crianças do início do século XX, Claudia Fonseca (1997) já notava tanto que a dita "família patriarcal extensa" concernia a "apenas uma pequena parcela da história brasileira" quanto que a urbanização não trouxe a nuclearização inevitável das famílias: “Muitas vezes, antes ao contrário, as redes de parentesco são fortalecidas, tornando-se indispensáveis para a integração dos trabalhadores na cidade" (Fonseca, 1997, p. 545). É assim que Fonseca ressalta a "circulação de crianças" como prática popular de cuidado cuja compreensão adequada requer a localização da maternagem nas redes sociais que perpassam a unidade doméstica - como acontece com Marcela, sua mãe e seus filhos.

Atualiza-se, aqui, a crítica elaborada por Mariza Corrêa (1981, p. 7) ao conceito de "família patriarcal", um "modelo ideal dominante, vencedor sobre várias formas alternativas que se propuseram concretamente no decorrer de nossa história", mas apenas um "modelo", como apontou Corrêa, e não uma descrição dos múltiplos modos cotidianos de vivenciar a organização familiar. O não cumprimento de um modelo não possui a priori o condão de ocasionar "problemas sociais", mas a anunciação de sua falta, especialmente a da "ausência do pai", acaba por transferir para as mulheres a responsabilidade pelo que seria a falência do modelo. É que, como notou Strathern (1995), a ideia de um filho sem pai não costuma provocar sentimentos de indignação moral. De fato, "os pais podem, na verdade, abandonar os filhos desde o nascimento sem serem vistos como monstros desnaturados ou ameaças ao sistema social" (Strathern, 1995, p. 311). Todavia, às mulheres, para quem a maternidade é construída como inconteste, é designado o lócus de guardiãs do modelo - ou, nas palavras de Strathern, do "ideal".

O general Mourão não se perguntava, em sua palestra, sobre o que faziam os pais cuja ausência ele notava às vésperas da eleição presidencial. O pai de Ricardo, por exemplo, está morto. Morreu à bala, em 2008, como morrem aqueles tipos matáveis de que falamos anteriormente, em meio ao "mata-mata"

7 Para acesso detalhado aos dados do IBGE acima mencionados, ver Velasco (2017). 
então característico do mercado de drogas ilícitas na Paraíba (Efrem Filho, 2017a; Mello, 2019). Deixou nos braços de Marcela um Ricardo de cinco anos de idade e um segundo filho do casal, com apenas um mês de nascido. Mas Mourão também não se perguntava sobre o destino dos pais de cuja ausência se ressentia. Ao sublinhar sua ausência, contudo, ele ressaltava a presença das mães e avós, aquelas que, implicadas no esforço diário do trabalho de cuidado, consistiriam numa "fábrica de elementos desajustados". Ainda que Mourão não haja intencionado ofender ou responsabilizar essas mulheres, como procurou explicar em declarações posteriores à imprensa, fato é que provocou um "constrangimento de Estado" que se não pôde mais desconsiderar na campanha eleitoral. Daí, afinal, o vídeo de Jair Bolsonaro acerca de sua esposa e de sua filha. Talvez seja possível dizer que, de alguma forma, ao engendrar uma acusação às "mais solteiras", Mourão tenha avançado num terreno arriscado contra aquela "história coletiva" de mulheres negociando os difíceis termos de suas trajetórias de maternidade. Essa história, acreditamos, encontra-se intimamente ligada à nossa experiência democrática.

\section{A “mãe" e os limites da democracia}

Sendo agente e objeto de controle, a "mãe" é também um sujeito imprescindível às nossas disputas democráticas. Nas décadas de 70 e 80 do século passado, quando, de acordo com Eder Sader (1988), "novos personagens entraram em cena" e o processo de redemocratização do país se adensou, os "clubes de mães" se somavam, por exemplo, ao novo sindicalismo, aos movimentos sociais urbanos e de saúde e às pastorais sociais e Comunidades Eclesiais de Base da Igreja Católica no desenvolvimento do que ficaria conhecido como o "trabalho de base" fundamental à reorganização política dos setores de esquerda no Brasil e às emergentes reivindicações de direitos que culminariam na Constituição de 1988.

Segundo Cynthia Sarti (1988), convenções morais em torno da maternidade compuseram centralmente essas mobilizações, sobretudo porque tal participação das "mulheres da periferia" na esfera pública acabou legitimando-se pelo seu pressuposto "papel de mãe". Motivadas pelo cumprimento desse papel, essas mulheres teriam buscado "melhorar as condições de vida de sua família, 
melhores oportunidades de educação e alimentação para seus filhos, através das lutas por melhorias urbanas no bairro, por creches, postos de saúde etc., diretamente vinculadas a seus problemas cotidianos de mãe de família" (Sarti, 1988, p. 43). Alianças entre essas "mães", movimentos de mulheres e feministas incidiram decisivamente no processo de redemocratização do país, ${ }^{8}$ nas movimentações acerca da Assembleia Constituinte e trouxeram, inclusive, como uma de suas consequências, a proteção constitucional à "família monoparental", aquela de regra formada pela mãe solo e por seus filhos.

Mais recentemente, durante o período de nossa história chamado por André Singer (2012) de "lulismo", as "mães" se transformaram em vetores fundamentais para as políticas de combate à fome e à miséria e de redução das desigualdades, como os já mencionados programas Minha Casa Minha Vida e Bolsa Família. Essas políticas de ampliação do acesso a direitos impactaram decisivamente nas vidas de mulheres como Marcela. Ocorreu que programas governamentais tais quais o Bolsa Família oportunizaram a essas mães alguma possibilidade de criar seus filhos (Fernandes, 2017; Klein, 2005). É que o programa "ajuda e muito", como disse Marcela a Roberto ainda em 2013, no quarto onde morava na Ocupação Horizonte. "Eu, bem dizer, sobrevivo com ele quando eu tou desempregada. No momento, eu tou desempregada, não tenho nada. Tou parada de tudo. Porque, às vezes, eu tou com duas, três faxinas. Hoje, eu tou sem nada. Eu tou só vivendo do meu dinheiro e do dinheiro da minha filha." Além do cuidado dos filhos, o Bolsa Família garantia que Marcela não precisasse submeter-se a relações muitíssimo precárias de trabalho que ela entendia como humilhantes ou análogas à escravidão.

Contudo, contraditoriamente, a condição de vetor para políticas públicas não livra essas mães da reatualização da condição de agente e objeto de controle. Camila Fernandes (2017) percebeu, por exemplo, que o Bolsa Família é tomado, em diferentes contextos sociais, como promotor de uma sexualidade feminina desregrada, com estímulo à procriação "irresponsável" e dependente. Nessa chave de interpretação da política pública, as legitimidades das

8 Como a literatura sobre o período aponta, essas alianças visavam desde a reinvindicações por creches até à unidade na oposição à ditadura civil-militar, mas não eram vividas sem tensões, notadamente em razão da íntima implicação de setores da Igreja Católica nos clubes de mães e movimentos urbanos e da rejeição religiosa a pautas feministas relacionadas ao aborto e à sexualidade (Diniz, 2018; Moraes, 1985; Sarti, 1988). 
mulheres que acessam o programa e dos direitos por ele proporcionados são postas sob suspeita através do acionamento de convenções morais de gênero e sexualidade que participam organicamente das dinâmicas dos conflitos de classe no país.

Por sua vez, essa condição de objeto e agente de controle também reaparece na análise desenvolvida por Bila Sorj (2016) acerca do engajamento de mulheres no Programa Mulheres da Paz, no Rio de Janeiro. O programa, iniciado ainda sob o segundo governo de Luiz Inácio Lula da Silva, visava à capacitação de mulheres moradoras de comunidades ou favelas para atuarem na prevenção e no enfrentamento da violência local, notadamente a que afeta mulheres e jovens. Dentre os objetivos do programa estava o "resgate de jovens" em "situação de risco". De acordo com Sorj (2016, p. 118), porém, "a construção simbólica dessa atividade, ao redor de valores associados ao feminino, suscita reflexões sobre o modo como o Estado, por meio das políticas sociais, contribui para manter ou reforçar normas tradicionais de gênero e desprofissionalizar o trabalho de cuidado".

Se isso acontecia num cenário de ampliação do acesso a direitos sociais e de consequente conflagração de sujeitos de direitos através da "mãe", agora, nos entremeios do que Flávia Biroli (2018) tem denominado de "nova conformação do neoliberalismo", a condição materna de objeto e agente de controle se adensa contundentemente, mas a ponto de tangenciar a ameaça de apagamento do sujeito. Isso porque essa nova conformação do neoliberalismo retoma a defesa da regulação pró-mercado dos anos 1990, acompanhada da redução de direitos sociais e investimentos públicos, mas com um conteúdo moral renovado. De acordo com Biroli (2018), ocorre que, para além da valorização do mérito pessoal, emerge aí uma ideologia antipluralista e anticosmopolita. Assim, em suas dinâmicas atuais, "o neoliberalismo parece recusar alguns de seus desenvolvimentos anteriores [...], em que ganharam legitimidade defesas do 'empoderamento' das mulheres e a relação entre igualdade de gênero, diversidade e desenvolvimento" (Biroli, 2018, p. 87).

Essa emergência ideológica recente se localiza no interior da "onda quebrada" (Almeida, 2019) do vertiginoso crescimento dos conservadorismos no país e se relaciona de perto com controvérsias públicas relativas a gênero e sexualidade, de que agentes religiosos têm participado incisivamente, como instigantes trabalhos vêm diagnosticando (Efrem Filho, 2019; Facchini; Sívori, 
2017; Leite, V., 2019; Machado, M., 2018). Marcas dessa participação se demonstram inclusive naquele pronunciamento de Jair Bolsonaro de 19 de setembro de 2018. Afinal, a adoção de uma "narrativa testemunhal" aciona um campo de possibilidades de diálogo e persuasão que se vem ampliando à medida que aumenta, como Raphael Bispo (2018, p. 251) notou, "a importância que os testemunhos religiosos enquanto estilos narrativos vêm adquirindo na esfera midiática diante do crescimento do pentecostalismo no Brasil". Para amenizar os efeitos negativos das declarações anteriores de Mourão e atestar publicamente o seu respeito às "mães solteiras", Bolsonaro trouxe a público, de lágrimas aos olhos e silêncios comovedores, um depoimento íntimo e emotivo em que não apenas testemunha haver casado com uma "mãe solteira" como confessa ter desfeito um procedimento de vasectomia - o que comprova a sua virilidade e não deixa de aludir a um processo de conversão. ${ }^{9}$

Entretanto, aquela emergência ideológica de que fala Flávia Biroli (2018) produz efeitos perversos, em especial, no cotidiano de mulheres como Marcela. Isso porque a restrição de direitos sociais, trabalhistas e previdenciários, a desregulamentação do trabalho e a redução de recursos públicos destinados às áreas de educação, saúde e assistência social comprometem, como Biroli (2018) tem entendido, as soluções de caráter público para os problemas diários do exercício do trabalho de cuidado.

A pressão para que as famílias assumam "suas" responsabilidades privadas se estabelece conjuntamente com a chamada ao restabelecimento da ordem de gênero. Torna-se imperativo produzir famílias "funcionais", isto é, responsabilizar novamente as mulheres por tarefas de que o Estado se esquiva, sobretudo no âmbito do cuidado, o que traz de volta o maternalismo - embora as mães reais, em sua maioria, quando têm filhos, lutem para deles cuidar em condições de precariedade, que se intensificam com o avanço das políticas neoliberais. (Biroli, 2018, p. 89).

9 Foge ao escopo deste artigo a exploração analítica da escolha da coordenação de campanha de Bolsonaro pelo testemunho como estilo narrativo para a sua tomada de posição acerca das "mães solteiras". Para interessantes análises das implicações entre testemunho, religiosidade, secularismo e mídias, sugerimos contudo a leitura dos trabalhos de Raphael Bispo (2018), Carly Machado (2014) e Mariana Côrtes (2014), os quais nos ajudaram na identificação estética do pronunciamento de Bolsonaro como testemunhal. 
A responsabilização privada das famílias - e, nelas, das "mães solteiras" para o trabalho de cuidado se desenlaça, desse modo, num contexto de cerceamento de políticas públicas imprescindíveis tanto para crianças e adolescentes quanto para suas mães. Com a negação do acesso a direitos, constrange-se reciprocamente a possibilidade de existência de sujeitos que se realizam através desses direitos ou das lutas sociais que os reivindicam e constroem. Se, contudo, seguindo Carla Villalta (2013) e Cecilia Montes-Maldonado (2020), nós lembramos que essa responsabilização privada das mães já consiste numa característica definidora das técnicas de "gestão da infância pobre", aquele movimento retórico empreendido por Hamilton Mourão de responsabilização das mães e avós pela origem dos "problemas sociais", num contexto da ressentida ausência do pai, torna-se ainda mais constrangedor. Nas políticas neoliberais, nas técnicas de gestão da infância e no discurso de Mourão, a "mãe" encarna a origem do problema, a inexorabilidade do destino do filho, a condição de objeto e agente de controle e a competência singular para performatizar uma prática de Estado. A "mãe" é prática de Estado diante do ressentimento masculino da ausência do "pai", diante da ausência de um "Estado" viabilizador do acesso a direitos.

Como Camila Fernandes (2017) percebeu, a ausência masculina e a ausência estatal são ativas, dotadas de agência, de modo que não devem ser compreendidas como faltas. Há presença na alegada ausência. Assim, segundo Fernandes (2017), a "ausência de Estado" engendra acontecimentos, oportuniza "virações", a dinamização de redes de ajuda e, de certo, desigualdades sociais e precariedades muitas vezes atribuídas às "figuras de causação". "O argumento de fundo expresso aqui consiste em significar que quando as ações de Estado não fazem, elas estão fazendo, imiscuídas nos silenciosos, solitários e enérgicos processos da vida cotidiana, muito palpáveis nas formas como as pessoas vão se ajeitar, arrumar e fazer seus mundos" (Fernandes, 2017, p. 59). Pois bem, essas pessoas que se arrumam para produzir seus mundos também partilham aquela "história coletiva" mencionada por Claudia Fonseca (2012). No que aqui tratamos mais diretamente, são mães que, organizadas ou não em movimentos sociais ou partidos políticos, consubstanciam um sujeito de direitos sociais, um sujeito político e eleitoral notável em nossa experiência democrática. No limite, elas votam.

A "mãe", portanto, mas notadamente a "mãe solteira", participa das disputas que conformam nossa frágil experiência democrática. Não à toa, o general 
Mourão direciona suas armas a ela com tamanha avidez. Igualmente não à toa, a coordenação da campanha de Jair Bolsonaro resolve desfazer os possíveis impactos negativos das declarações do general e passa a investir na legitimação da "mãe solteira", aquela com quem Jair Bolsonaro casou, aquela que é mãe de sua filha, em razão de quem ele decidiu desfazer a sua vasectomia porque, enfim, havia a necessidade de "manutenção do casamento" e o "sonho de muitas mulheres é ter filhos". Claro, a resolução da coordenação de campanha de aproximar o candidato às mulheres - a "esposa", a "mãe", a "filha" - também responderia às mobilizações que terminaram por acarretar os grandes atos públicos, protagonizados por mulheres, que tomaram as grandes cidades do país em 20 de outubro de 2018 e cuja palavra de ordem aglutinadora era o "Ele Não". Mas, parece-nos, mais profundamente, o vídeo de um Bolsonaro comovido e mudo, durante segundos, diante da câmera aponta sobremaneira para o reconhecimento da necessidade de disputa sobre o sujeito político "mãe".

Trata-se, entretanto, de uma disputa que, arriscamos dizer, Jair Bolsonaro não venceu tão obviamente nas últimas eleições presidenciais, isso se venceu. Marcela, afinal, votou em Fernando Haddad. Cruzando os dados da última pesquisa do Datafolha publicada em 18 de outubro de 2018, dias antes das eleições, na Paraíba, em Pernambuco, nos estados da região Nordeste, mas também no Brasil, mulheres com a posição de classe de Marcela, com renda de até dois salários mínimos, com grau de escolaridade até o ensino fundamental, votaram sobretudo em Haddad. Mais. Se descermos a idade dessas mulheres para o espectro entre 16 e 24 anos, veremos que a possibilidade de elas haverem votado em Haddad é ainda maior. Marcela consubstancia o grupo social com maior probabilidade de haver votado em Fernando Haddad, contra Jair Bolsonaro. A variável negativa, importa saber, relaciona-se apenas às mulheres autoidentificadas como evangélicas, já que os evangélicos consistiram no grupo religioso em que Bolsonaro alcançou maior diferença de votos em relação a Haddad. ${ }^{10}$

Mulheres como Marcela eram, elas sim, as "fábricas de desajustados" de que falou o general Mourão, mães e avós cujas experiências de classe (e racialização, por certo) aproximam-se das experiências de Marcela. As mesmas que se

10 Para acesso aos dados detalhados por segmento da pesquisa do Datafolha de 18 de outubro de 2018, ver Pesquisa... (2018). 
transformaram, no período lulista, naqueles vetores fundamentais de acesso a direitos e de redução das desigualdades sociais. As mesmas mulheres cujo inexorável destino materno é imprescindível para o exercício do controle, prática de Estado. As mesmas, enfim, que têm povoado nossos trabalhos a respeito da implicação de "mães" em lutas por direitos e justiça. As mesmas que protagonizam diversos movimentos sociais e lideram ocupações de sem-teto e de sem-terra.

A tentativa de Bolsonaro de amenizar os efeitos das declarações de Mourão, portanto, disputava a "mãe" e, sobretudo, a "mãe solteira", mas afastando-as de Marcela. A atual esposa de Bolsonaro, afinal, também mãe solo, corporifica uma outra mãe, que serve devidamente à comprovação de que o problema por excelência não está em ser "mãe solteira" abstratamente, em tese, mas em ser "mãe solteira" como Marcela. O problema está em Marcela, na "história coletiva" que ela encarna. Bolsonaro, dessa maneira, disputa a mãe ao tempo que disputa relações de classe e racialização (inclusive, novamente, a conformação de corpos e territórios mais ou menos disponíveis à violência), e o faz ao tempo que disputa, em última instância, o conteúdo do sujeito político "mãe" e, assim, os limites de nossa experiência democrática.

\section{Referências}

ALMEIDA, R. de. Bolsonaro presidente: conservadorismo, evangelismo e a crise brasileira. Novos Estudos Cebrap, São Paulo, v. 38, n. 1, p. 185-213, 2019.

ARAÚJO, F. A. Do luto à luta: a experiência das mães de Acari. 2007. Dissertação (Mestrado em Sociologia e Antropologia) - Instituto de Filosofia e Ciências Sociais, Universidade Federal do Rio de Janeiro, Rio de Janeiro, 2007.

BIRMAN, P.; PIEROBON, C. Viver sem guerra? Poderes locais e relações de gênero no cotidiano popular. Revista de Antropologia, São Paulo, v. 64, n. 2, e186647, 2021.

BIROLI, F. Reação conservadora, democracia e conhecimento. Revista de Antropologia, São Paulo, v. 61, n. 1, p. 83-94, 2018.

BISPO, R. Na corrente midiática da fé: comunicação de massa e dinâmicas contemporâneas do testemunho evangélico. Horizontes Antropológicos, Porto Alegre, ano 24, n. 52, p. 249-277, 2018. 
CESARINO, L. Identidade e representação no bolsonarismo: corpo digital do rei, bivalência conservadorismo-neoliberalismo e pessoa fractal. Revista de Antropologia, São Paulo, v. 62, n. 3, p. 530-557, 2019.

CORREA, M. Repensando a família patriarcal brasileira: notas para o estudo das formas de organização familiar do Brasil. Cadernos de Pesquisa, São Paulo, n. 37, p. 5-16, 1981.

CÔRTES, M. O mercado pentecostal de pregações e testemunhos: formas de gestão do sofrimento. Religião \& Sociedade, Rio de Janeiro, v. 34, n. 2, p. 184-209, 2014.

COSTA, S. G. Proteção social, maternidade transferida e lutas pela saúde reprodutiva. Revista Estudos Feministas, Florianópolis, v. 10, n. 2, p. 301-323, 2002.

CRUZ, F. Da maternidade como invenção de novas possibilidades de vida: análise das experiências de jovens "egressas" de serviços de acolhimento institucional. Civitas, Porto Alegre, v. 15, n. 2, p. 326-341, 2015.

DINIZ, C. A. N. O protagonismo das mulheres nos movimentos sociais da periferia: memórias e experiências dos Clubes de Mães da zona sul de São Paulo (1972-1988). 2018. Tese (Doutorado em História) - Faculdade de Ciências e Letras de Assis, Universidade Estadual Paulista, Assis, 2018.

EFREM FILHO, R. Mata-mata: reciprocidades constitutivas entre classe, gênero, sexualidade e território. 2017. Tese (Doutorado em Ciências Sociais) - Instituto de Filosofia e Ciências Humanas, Universidade Estadual de Campinas, Campinas, 2017a.

EFREM FILHO, R. A reivindicação da violência: gênero, sexualidade e a constituição da vítima. Cadernos Pagu, Campinas, n. 50, e175007, 2017b.

EFREM FILHO, R. Os meninos de Rosa: sobre vítimas e algozes, crime e violência. Cadernos Pagu, Campinas, n. 51, e175106, 2017c.

EFREM FILHO, R. "Os evangélicos" como nossos "outros": sobre religião, direitos e democracia. Religião \& Sociedade, Rio de Janeiro, v. 39, n. 3, p. 124-151, 2019.

FACCHINI, R.; SÍVORI, H. Conservadorismo, direitos, moralidades e violência: situando um conjunto de reflexões a partir da Antropologia. Cadernos Pagu, Campinas, n. 50, e175000, 2017.

FARIAS, J. Governo de mortes: uma etnografia da gestão de populações de favelas no Rio de Janeiro. 2014. Tese (Doutorado em Sociologia e Antropologia) - Instituto de Filosofia e Ciências Sociais, Universidade Federal do Rio de Janeiro, Rio de Janeiro, 2014. 
FARIAS, J.; LAGO, N. B. do; EFREM FILHO, R. Mães e lutas por justiça. Encontros entre produção de conhecimento, ativismos e democracia. Sexualidad, Salud y Sociedad: revista latinoamericana, Rio de Janeiro, n. 36, p. 146-180, 2020.

FELTRAN, G. Fronteiras de tensão: política e violência nas periferias de São Paulo. São Paulo: Editora Unesp: CEM: Cebrap, 2011.

FELTRAN, G. Formas elementares da vida política: sobre o movimento totalitário no Brasil (2013-). In: NOVOS Estudos Cebrap [Blog]. São Paulo: Cebrap, 2020. Disponível em: http://novosestudos.com.br/formas-elementares-da-vida-politica-sobre-o-movimento-totalitario-no-brasil-2013/. Acesso em: 23 set. 2020.

FERNANDES, C. Figuras de causação: sexualidade feminina, reprodução e acusações no discurso popular e nas políticas de Estado. 2017. Tese (Doutorado em Antropologia Social) - Museu Nacional, Universidade Federal do Rio de Janeiro, Rio de Janeiro, 2017.

FONSECA, C. Ser mulher, mãe e pobre. In: DEL PRIORI, M. (org.). História das mulheres no Brasil. São Paulo: Contexto, 1997. p. 510-553.

FONSECA, C. Mães “abandonantes”: fragmentos de uma história silenciada. Revista Estudos Feministas, Florianópolis, v. 20, n. 1, p. 13-32, 2012.

KLEIN, C. A produção da maternidade no Programa Bolsa-Escola. Revista Estudos Feministas, Florianópolis, v. 13, n. 1, p. 31-52, 2005.

LACERDA, P. M. O sofrer, o narrar e o agir: dimensões da mobilização social de familiares de vítimas. Horizontes Antropológicos, Porto Alegre, ano 20, n. 42, p. 49-75, 2014.

LAGO, N. B. do. Jornadas de visita e luta: tensões, relações e movimentos de familiares nos arredores da prisão. 2019. Tese (Doutorado em Antropologia Social) - Faculdade de Filosofia, Letras e Ciências Humanas, Universidade de São Paulo, São Paulo, 2019.

LEITE, M. P. As mães em movimento. In: BIRMAN, P.; LEITE, M. P. (org.). Um mural para a dor: movimentos cívico-religiosos por justiça e paz. Porto Alegre: Editora da UFRGS, 2004. p. 141-190.

LEITE, V. “Em defesa das crianças e da família”: refletindo sobre discursos acionados por atores religiosos "conservadores" em controvérsias públicas envolvendo gênero e sexualidade. Sexualidad, Salud y Sociedad: revista latinoamericana, Rio de Janeiro, n. 32, p. 119-142, 2019.

LEITE, I. L. da S.; MARINHO, C. H. Redes de resistência e esperança. Narrativas de mães do Ceará que lutam por reconhecimento, memória e amor. Sexualidad, Saludy Sociedad: revista latinoamericana, Rio de Janeiro, n. 36, p. 343-362, 2020. 
LUGONES, M. G. ¿Matronato? Gestiones maternales de protección estatal. Cadernos Pagu, Campinas, n. 51, e175102, 2017.

MACHADO, C. Pentecostalismo e o sofrimento do (ex-)bandido: testemunhos, mediações, modos de subjetivação e projetos de cidadania nas periferias. Horizontes Antropológicos, ano 20, n. 42, Porto Alegre, p. 153-180, 2014.

MACHADO, M. das D. C. O discurso cristão sobre a "ideologia de gênero". Revista Estudos Feministas, Florianópolis, v. 26, n. 2, e47463, 2018.

MALLART, F. Cadeias dominadas: a Fundação CASA, suas dinâmicas e as trajetórias de jovens internos. São Paulo: Terceiro Nome, 2014.

MARIANO, S. A.; CARLOTO, C. M. Gênero e combate à pobreza: Programa Bolsa Família. Revista Estudos Feministas, Florianópolis, v. 17, n. 3, p. 901-908, 2009.

MELLO, B. M. de. Na selva de pedras: as performances de gênero e sexualidade nos conflitos entre prostituição, crime e Estado. 2019. Dissertação (Mestrado em Ciências Jurídicas) - Centro de Ciências Jurídicas, Universidade Federal da Paraíba, João Pessoa, 2019.

MONTES-MALDONADO, C. Cuidados como categoría de análisis y orientación de las medidas socioeducativas para adolescentes en Uruguay. Oñati Socio-Legal Series, Oñati, v. 10, n. 2, p. 363-387, 2020.

MORAES, M. L. Q. de. Mulheres em movimento. São Paulo: Nobel: Conselho Estadual da Condição Feminina, 1985.

NANES, G.; QUADROS, M. T. de. Programa Bolsa Família, mercado de trabalho e agência de mulheres titulares do Coque (Recife-PE). Cadernos Pagu, Campinas, n. 52, e1852209, 2018.

PESQUISA Datafolha de 18 de outubro para presidente por sexo, idade, escolaridade, renda, região e religião. G1, 19 out. 2018. Disponível em: https://g1.globo.com/ politica/eleicoes/2018/eleicao-em-numeros/noticia/2018/10/19/pesquisa-datafolha-de-18-de-outubro-para-presidente-por-sexo-idade-escolaridade-renda-regiao-e-religiao.ghtml. Acesso em: 21 set. 2020.

PINHEIRO, D. A. de J. P.; LONGHI, M. R. Maternidade como missão! A trajetória militante de uma mãe de bebê com microcefalia em Pernambuco. Cadernos de Gênero e Diversidade, Salvador, v. 3, n. 2, p. 113-132, 2017.

PIRES, A. Orçamento familiar e gênero: percepções do Programa Bolsa Família. Cadernos de Pesquisa, São Paulo, v. 42, n. 145, p. 130-161, 2012. 
RIBEIRO, D. de S. Rebelião das mães. Ética do cuidado em coletivo face à necropolítica no encarceramento de adolescentes. Sexualidad, Salud y Sociedad: revista latinoamericana, Rio de Janeiro, n. 36, p. 255-274, 2020.

ROCHA, L. L. C. da. "As cumades das facções": as relações de gênero e sexualidade dentro das facções Okaida e Estados Unidos em João Pessoa. 2016. Dissertação (Mestrado em Direito) - Centro de Ciências Jurídicas, Universidade Federal da Paraíba, João Pessoa, 2016.

SADER, E. Quando novos personagens entram em cena: experiências, falas e lutas dos trabalhadores da Grande São Paulo, 1970-80. Rio de Janeiro: Paz e Terra, 1988.

SARTI, C. Feminismo no Brasil: uma trajetória particular. Cadernos de Pesquisa, São Paulo, n. 64, p. 38-47, 1988.

SCOTT, R. P.; LIRA, L. C. de. A gestão do tempo no tempo da emergência: o cotidiano das mães e crianças afetadas pela Síndrome Congênita do Zika. Ayé: revista de antropologia, Acarape, v. 2, n. 1, p. 14-29, 2020.

SINGER, A. Os sentidos do lulismo: reforma gradual e pacto conservador. São Paulo: Companhia das Letras, 2012.

SORJ, B. Políticas sociais, participação comunitária e a desprofissionalização do care. Cadernos Pagu, Campinas, n. 46, p. 107-128, 2016.

STRATHERN, M. Necessidade de pais, necessidade de mães. Revista Estudos Feministas, Florianópolis, v. 3, n. 2, p. 303-329, 1995.

VELASCO, C. Em 10 anos, Brasil ganha mais de 1 milhão de famílias formadas por mães solteiras. G1, 14 maio 2017. Disponível em: https://g1.globo.com/economia/noticia/em-10-anos-brasil-ganha-mais-de-1-milhao-de-familias-formadas-por-maes-solteiras.ghtml. Acesso em: 21 set. 2020.

VIANNA, A. Limites da menoridade: tutela, família e autoridade em julgamento. 2002. Tese (Doutorado em Antropologia Social) - Museu Nacional, Universidade Federal do Rio de Janeiro, Rio de Janeiro, 2002a.

VIANNA, A. Quem deve guardar as crianças? dimensões tutelares da gestão contemporânea da infância. In: SOUZA LIMA, A. C. de (org.). Gestar e gerir: estudos para uma antropologia da administração pública no Brasil. Rio de Janeiro: Relume Dumará: Nuap/UFRJ, 2002b. p. 271-311.

VIANNA, A. Violência, Estado e gênero: entre corpos e corpus entrecruzados. In: SOUZA LIMA, A. C. de; GARCIA-ACOSTA, V. (org.). Margens da violência: subsídios ao estudo do problema da violência nos contextos mexicano e brasileiro. Brasília: ABA, 2014. p. 209-237. 
VIANNA, A.; FARIAS, J. A guerra das mães: dor e política em situações de violência institucional. Cadernos Pagu, Campinas, n. 37, p. 79-116, 2011.

VIANNA, A.; LOWENKRON, L. O duplo fazer do gênero e do Estado: interconexões, materialidades e linguagens. Cadernos Pagu, Campinas, n. 51, e175101, 2017.

VILLALTA, C. Un campo de investigación: las técnicas de gestión y los dispositivos jurídico-burocráticos destinados a la infancia pobre en la Argentina. Civitas, Porto Alegre, v. 13, n. 2, p. 245-268, 2013.

Recebido: 30/09/2020 Aceito: 06/07/2021 | Received: 9/30/2020 Accepted: 7/6/2021 